Alberto Boretti*

\title{
State-of-the-art of MW-level capacity oceanic current turbines
}

https://doi.org/10.1515/nleng-2020-0022

Received Feb 26, 2018; accepted Mar 11, 2019.

\begin{abstract}
Marine hydrokinetic turbines of MW-level capacity for harvesting oceanic currents are here reviewed. The best design is 3-blades, open rotor, axial flow turbines, of similar design philosophy to wind turbines, which are anchored to the ocean floor. The best locations are those with the oceanic current resource of higher intensity and stability, non-excessive depth of the ocean floor, proximity to shore, and favorable topography. In these locations, marine hydrokinetic turbines may become competitive with other renewable energy alternatives. It is expected that such turbines will be installed and will start producing electricity, within the next decade, working with power coefficients, the ratio of electric power from the turbine to wind power, around 0.45 , similarly to wind turbines. This will pave the road for further progress and significant uptake of technology so far of no impact on the global energy mix.
\end{abstract}

Keywords: hydrodynamic, oceanic currents, axial flow turbines, capacity factors

\section{Introduction}

According to the International Energy Agency Key world energy statistics 2018 [1], in 2016 the World Total Primary Energy Supply (TPES) by fuel was Oil, 31.9\%; Coal (counting pet and oil shale), 27.1\%; Natural Gas, 22.1\%; Biofuels and Waste, 9.8\%; Nuclear, 4.9\%; Hydro, 2.5\% and Others (Renewables) 1.7\%. Others include wind, geothermal, solar, tide/wave/ocean, heat, and other renewables. Hence, the TPES by renewables is still small, but it is becoming sizeable especially as wind, and more recently solar photovoltaics.

The situation is more favorable if we consider electricity generation. According to the International Energy

*Corresponding Author: Alberto Boretti, Department of Mechanical Engineering, College of Engineering, Prince Mohammad Bin Fahd University, Al Khobar, Saudi Arabia, E-mail: a.a.boretti@gmail.com
Agency [1], in 2016 the World electricity generation by the source was Coal, 38.4\%; Natural Gas, 23.2\%; Hydro, 16.3\%; Nuclear, 10.4\%; Oil, 3.7\%; non-hydro Renewable and Waste, $8.0 \%$. Non-Hydro Renewable and Waste include not only wind, but also geothermal, solar, tide/wave/ocean, and more importantly, biofuels, waste, and other renewables. In terms of electricity, wind energy now starts to provide significant contributions in many countries.

According to the U.S. Energy Information Administration [2], in 2017 the annual net generation for all sectors has been $4.01 \cdot 10^{6} \mathrm{GWh}$, with major contributions from coal (30.09\%), natural gas (31.70\%) and nuclear $(20.05 \%)$ - Figure 1 - but now already 6.33\% from wind, and 1.93\% all solar.

In 2001, the first year of the statistic, the annual net generation for all sectors was $3.74 \cdot 10^{6} \mathrm{GWh}$, with a much larger contribution from coal (50.95\%), a smaller contribution from natural gas $(17.10 \%)$ and about the same contribution from nuclear (20.58\%), but only $0.18 \%$ from wind, and $0.00 \%$ all solar.

The goal of ocean energy is to follow the path highlighted by wind energy, which is providing a measurable contribution to the global energy mix, but this is easily said than done.

Ocean energy, [3-5], includes the energy carried by ocean tides, waves, currents, salinity, and ocean temperature difference. Tidal energy has been so far the most exploited energy of this pool [4]. The worldwide production of tidal energy electricity is still minimal, and the very few installations realized so far, are characterized by large environmental and economic costs. Ocean energy has presently no measurable contribution to the global energy mix. Tidal energy is, however, a much more established technology than the other ocean energy technologies. The exploitation of ocean energy has been so far very limited, with efforts mostly focused on the tidal motion of large bodies of water, and surface wave powers.

Historically, tide mills have been since the Roman times, with then some examples of harvesting from the Middle Ages, and more recent examples up to the nineteen centuries in Europe and the east coast of North America. The world's first tidal power plant was the "La Rance" power station in France, completed in 1966. 


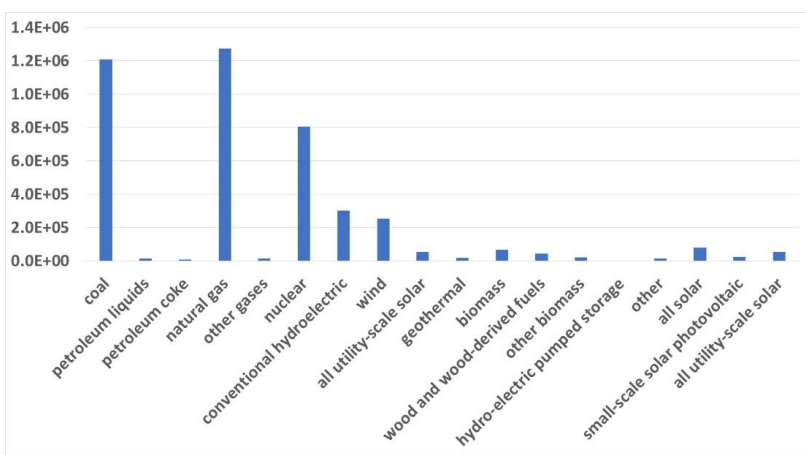

(a)

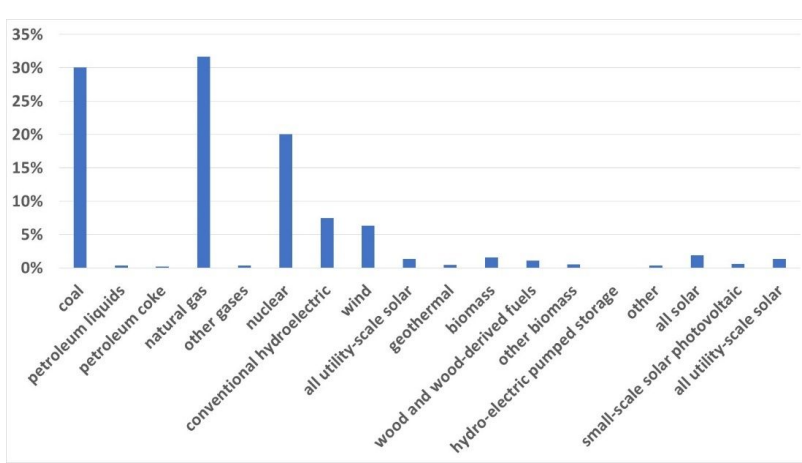

(b)

Figure 1: Electricity generation in the U.S. by source, 2017 data from [2]; a) generation in $\mathrm{GWh}$; b) generation in the percentage of the total

The theoretical global ocean energy resources are listed in Table 1. While all these values may be regarded as optimistic, the potential of the marine currents is certainly much larger than tidal.

Oceanic currents may have a much larger potential than tidal. The movement of water in the oceans creates a large amount of energy that in principle can be harnessed to generate electricity, [3-5].

While tides are driven by the gravitational force of the moon and sun, oceanic currents are driven by several factors including the rise and fall of the tides, wind and thermo-haline circulation driven by density differences in water due to temperature (thermo) and salinity (haline).

The relatively constant flow of ocean currents carries large amounts of water across the earth's oceans. Ocean currents move slowly compared to typical wind speeds, but they carry a great deal of energy because of the density of the water. Deep ocean currents may run even at a constant speed of about 3 to 5 knots, or 5.5 to $9 \mathrm{~km} / \mathrm{h}$, or 1.5 to $2.5 \mathrm{~m} / \mathrm{s}$. Strong currents can be found within a few kilometers from shore also at relatively easy-to-reach depths of 30 to 150 meters. Ocean currents are relatively constant and flow in one direction, in contrast to tidal currents along the shore. However, the bathymetry of the ocean floor and the actual velocity distribution is mostly unknown.

The actual speed of the oceanic currents at different depths may drastically differ from the values proposed by global circulation models [6]. They may be subjected to large fluctuations in intensity and directions, with different time scales, requesting accurate velocity measurements before siting. Additionally, the bathymetry of the most part of the oceans even close to shore is unknown.

For example, in Australia, ocean currents off the East coast offer a potentially large energy resource, but the harvesting of this resource still faces several technological and oceanographic challenges [6]. There is no industrial turbine presently available and ready to be deployed. There is not enough information to properly sit these turbines. Financing of even demonstration projects is difficult.

While ocean currents have the potentials of better than tidal environmental and economic costs and could, therefore, provide a sizeable contribution to the global energy mix in the next few decades [3], [5], the technology is still in its infantry.

The aim of the paper is to review the technology for oceanic current turbines.

\section{Theory of hydrodynamic turbines}

NREL [7] proposes the use of the same aerodynamic tools for the design of horizontal-axis wind and general marine hydrokinetics turbines including oceanic current turbines.

While the incompressible flow equations certainly well represent both applications, the rotor blade profiles for oceanic currents may differ considerably from the profiles used in wind turbines, as the rotor must be made much smaller, but also much stronger.

The power that may be harvested by an axial flow wind turbine is proportional to the wind power

$$
P=\frac{1}{2} \rho \cdot A \cdot c^{3}
$$

where $\mathrm{P}$ is the power, $\rho$ the air density, A the swept area of the turbine and $c$ the wind speed. The proportionality factor is the power coefficient $\eta$.

Albert Betz [8] concluded in 1919 that from an aerodynamic perspective, no wind turbine can convert more than 16/27 (59.3\%) of the kinetic energy of the wind into mechanical energy turning a rotor (Betz Limit). Betz assumed that the average wind speed through the rotor area is the average of the undisturbed wind speed before the wind turbine, $c_{1}$, and the wind speed after the wind tur- 
Table 1: Theoretical global ocean energy resources [5]

\begin{tabular}{ccc}
\hline Capacity (GW) & Annual gen. $(T W \cdot h)$ & Form \\
\hline 5,000 & 50,000 & Marine current \\
\hline 20 & 2,000 & Osmotic salinity gradient energy \\
\cline { 2 - 3 } 1,000 & 10,000 & Ocean thermal energy \\
\cline { 2 - 3 } $1,000-9,000$ & 800 & Tidal \\
\hline
\end{tabular}

bine, $c_{2}$, i.e. $\frac{1}{2} \cdot\left(c_{1}+c_{2}\right)$. If the mass flow rate across the turbine is taken as:

$$
\dot{m}=A_{12} \cdot \rho \cdot \frac{\left(c_{1}+c_{2}\right)}{2}
$$

with $A_{12}$ is the rotor swept area, the wind power extracted by the rotor (Newton's second law) is then

$$
P=\dot{m} \cdot \frac{\left(c_{1}^{2}-c_{2}^{2}\right)}{2}
$$

The ratio between the power extracted from the wind and the power in the undisturbed wind flow is thus:

$$
\frac{P}{P^{\star}}=\frac{1}{2} \cdot \frac{\left(c_{1}+c_{2}\right)}{c_{1}} \cdot \frac{\left(c_{1}^{2}-c_{2}^{2}\right)}{c_{1}^{2}}
$$

Betz demonstrated that this function has a maximum of $16 / 27$ for $c_{2} / c_{1}=1 / 3$ (Betz's limit). The Betz's limit is the maximum aerodynamic efficiency that may be provided by a wind turbine, hereafter $\eta_{a}$.

The power coefficient (or global efficiency) of a wind turbine $\eta$ is then the product of aerodynamic, mechanical transmission and mechanical to electric energy conversion efficiencies, respectively $\eta_{a}, \eta_{m}$, and $\eta_{e}$.

While ducted turbines have been proposed also for wind, they are much easier to be built for oceanic turbines. Ducted turbines may have aerodynamic efficiencies in excess of the Betz's limit.

For an oceanic current turbine, we do have:

$$
P=\eta \cdot \frac{1}{2} \cdot \rho \cdot A \cdot c^{3}
$$

with $\rho$ the water density, and $\eta$ is the power coefficient. $\eta$ is certainly less than 0.593 for an open turbine, because of the Betz' limit $\eta_{a}$, the mechanical energy transmission efficiency $\eta_{m}$ and the mechanical to electric energy conversion efficiency $\eta_{e}$ that further limit the power coefficient

$$
\eta=\eta_{a} \cdot \eta_{m} \cdot \eta_{e}
$$

However, with ducted turbines, $\eta_{a}$ may exceed the Betz's limit, and also the power coefficient can be made larger than the Betz's limit.

Traditional open wind turbines cannot operate at the Betz limit, as aerodynamic, mechanical energy transmission and mechanical to electric energy conversion efficiencies, all limit the operating power coefficient well below this limit. Similarly, to open wind turbines, open oceanic current turbines are expected to operate well below the Betz's limit.

By simply adopting a partially or completely “ducted”, rather than "open", design, the oceanic turbine may operate with an aerodynamic efficiency larger than the Betz's limit. For example, the "diffuser" of the SMART mono float [9], a small 5-kW river turbine, that is actually a convergent nozzle protecting the generator as well as increasing the water velocity when passing through it, the Betz's limit can be exceeded.

Comparing the SMART mono float with the SMART freestream of the same rotor [9], as shown later, performances for the same freestream speed of the water improve. For the sake of simplicity, we can thus assume:

$$
\eta=\eta_{a} \cdot(1+\epsilon) \cdot \eta_{m} \cdot \eta_{e}
$$

Where $\alpha$ is an efficiency augmentation factor accounting changes of the entry velocity to the rotor vs. the freestream velocity [10].

While for wind turbines it is appropriate to use equation (6) for the power coefficient, for oceanic current turbines it is more appropriate to use equation (8).

Hydrokinetic ducted turbines are much simpler to build than ducted wind turbines, that despite proposed by many, haven't reached so far any significant deployment for the many downfalls. The increased energy conversion efficiency of simply shrouded hydrokinetic turbines is also discussed in [11].

Significant differences in between hydrokinetic and wind turbines exist in their control, as it is slightly harder to change the blade setting, and in some extent, the speed of the rotor, in hydrokinetic turbines, to adapt to the changing freestream wind or water flow conditions, even if everything but dramatic.

Having much larger hub diameters and much smaller rotor diameters, the blockage effect, albeit sometimes compensated by the flow acceleration, translate in a significant reduction of the actual rotor cross-sectional area vs. the reference rotor area considered in the Betz's limit.

Marine turbines are designed by using the same principles as wind turbines, with the significant difference of 
the much higher density of the water versus the density of the air and the much higher surrounding pressure, the smaller diameter of the rotor and the closer proximity to the ocean floor.

The aerodynamic design of a wind turbine rotor is performed using Blade Element Momentum Theory (BEMT), as discussed in [12-14], where the power produced by the turbine is correlated to the aero/hydrodynamic forces acting on every section of the rotor blades.

Ref. [15] describes a robust BEMT implementationspecific for oceanic current turbines. The basic model has been improved to better predict the performance of a marine rotor under a range of operating conditions, from start-up, through normal operation, to over speed and propeller brake state. The manuscript uses the Prandtl tip and hub loss corrections to improve accuracy when compared to a lifting line theory model.

The free NREL software Aerodyn [16] uses the BEMT method to analyze rotors of wind turbines and marine current turbines. In Aerodyn, the airfoil information includes the angle of attack, the lift coefficient, the drag coefficient. Correlations are used for tip and hub losses. Different rotors are considered in the validation, many for wind, and two for marine hydrokinetic applications. The two marine hydrokinetic rotor blades are the Doman [17] and the Bahaj [18] rotors discussed later.

If BEMT simulations of pre-defined aerofoil sections stacked to form a rotor blade are necessary steps to design a rotor, experiments and Computational Fluid Dynamic simulations may then be used to better analyze the rotor performances including fluid viscosity, turbulence, nonuniformity of intake flow.

The Computational Fluid Dynamic (CFD) simulations of [6], refer to a rotor of diameter $5.65 \mathrm{~m}$ at a depth of $300 \mathrm{~m}$ at the axis of the nacelle. The rotor blade profiles are simplistic circular arcs, and the blade length is reduced when compared to the diameter of the nacelle. The distance of the axis of the nacelle from the ocean floor is not enough to cancel the effects of the boundary layer on the energy harvesting of the turbine. Hydrodynamic power coefficient values of around 0.30-0.40 are found over the expected range of speeds. These values are worse than the values of top-of-the-class wind turbines, where the maximum power coefficient is around 0.45-0.5 [19, 20].

\section{Sample designs of small scale marine hydrokinetic turbines}

The turbine technology is still immature for tidal power, and still non-assessable for oceanic currents, still lacking a reliable industrial product. The tidal energy harvesting technologies that are known to the European Marine Energy Centre (EMEC) [21] includes 94 entries. The immature nature of the industry makes it difficult for the categorization of the devices made. Of these 94 entries, about one half, 45, are classified as Horizontal Axis Turbine, 14 are Vertical Axis Turbines, 4 are Oscillating Hydrofoil, 3 are Enclosed tips (Venturi), 3 are Tidal Kite, 2 are Archimedes Screw. There are then 11 turbines classified as Others and the rest are unclassified.

Tides are long-period waves, that result in the cyclical rise and fall of the ocean's surface. Tides produce different sea levels from one place on the continental shelf to the next at any one time, and this causes the water column to flow horizontally back and forth over the shelf. Tides contain both potential energies related to the vertical fluctuations in sea level and kinetic energy, related to the horizontal motion of the water column that can both be harvested with different technologies.

Tidal power can be harvested by using tidal stream generators that make use of the kinetic energy of moving water to power turbines in a similar way to wind turbines, that use the wind to power turbines. Alternatively, tidal barrages make use of the potential energy in the difference in head between high and low tides, however with a much large environmental and economic impact.

While tidal stream generators should be designed double direction to better collect the tidal energy, but they are designed in a single direction, the oceanic current stream generators will have to deal with a stream in one direction only. Most coastal areas, with some exceptions, experience two high tides and two low tides every 24 hours and 50 minutes (the lunar day, [22]). In the best locations, at every high tide, significant volumes of water flow through the strait at a relatively high speed of 2.5 to $3 \mathrm{~m} / \mathrm{s}$, and at low tide, the water flows back into the sea. The flow is discontinuous but predictable, and it is repeated twice each day. Opposite, the oceanic currents are continuous, but usually with reduced speed.

A survey of tidal turbines is proposed in [23], covering bare, ducted, and open-center turbines. For axial flow, substantial decreases in power generated by the ducted and open-center turbines were found, relative to a bare turbine of equal total device diameter. For open-center turbines, an increase in aperture size leads to a further re- 
duction in power generated. The increased blockage was shown to positively affect the performance of all devices. Moderate increases in power density (power divided by rotor area) is achieved for the ducted and open-center devices. For yawed inflow, the performance of the bare turbine decreases, whereas the performance of ducted and open-center turbines increases.

Oceanic currents may be harvested with standalone stream turbines similarly to the stream turbines for tidal currents, however with significant differences. Oceanic current turbines should be reasonably placed on the bottom of the ocean floor, at much more significant depths. Oceanic current turbines do not benefit from being a double direction. There may be much more similarity between oceanic current turbines and wind turbines, than wind and tidal turbines.

The oceanic current energy is now receiving growing attention, as demonstrated by the many recent works on the subject and the growing number of start-up companies dealing with the harvesting of the energy of oceanic currents, [24-26]. However, the harvesting techniques are still far from being consolidated technologies, and of the many different options that have been proposed, very likely only very few will progress.

In Ref. [24] it was pointed out as at the time (2003) no work was done to determine the characteristics of turbines running in water for kinetic energy conversion even though relevant work has been carried out on ship's propellers, wind turbines and on hydro turbines. The paper reported specific issues such as the harsh marine environment, the phenomenon of cavitation, and the high stresses encountered by such structures, that need to be addressed.

One activity of relevance has been the one conducted by the researchers at Florida Atlantic University (FAU), $[25,26]$. They studied the ocean currents along Florida's southeast coast and determined practical turbine operating areas that maximize energy extraction. The study was based on open-flow devices placed on the ocean floor.

Only a small number of prototypes and demonstration units have been tested, and prototype horizontal axis turbines, like wind turbines, have been the solution more widely built and tested.

The fundamental laws that apply to wind turbines also apply in principle to stream turbines designed to harvest the ocean currents. However, for ocean current energy to be utilized successfully at a commercial scale, several engineering and technical challenges need to be addressed including very high hydrostatic pressures, saltwater, avoidance of cavitation (if in shallow waters), prevention of marine growth builds up, system reliability and cor- rosion resistance and more generally all the issues linked to the operation in harsh environments.

Deep oceans turbines may deliver less than wind turbines in terms of power coefficient due to the operation in a particularly harsh environment, the much closer proximity of the rotor to the ocean floor, and the different degree of optimization.

Ref. [27] discusses the drawbacks of hydrokinetic technologies, namely relatively low efficiency, cavitation (for tidal applications) and harsh marine environment. The efficiency of hydrokinetic turbines is far from that of conventional hydrostatic systems. While water to wire efficiency can exceed 0.8 to 0.9 levels in dams, hydrokinetic turbines can barely achieve 0.35 .

The research turbine of [25] is an open, axial flow turbine with one rotor, has a power coefficient of 0.36 . The rotor diameter is approximately 3 meters, and the overall length of the turbine is approximately 2.5 meters. The rotor has 3 blades. The turbine may produce $20 \mathrm{~kW}$ of electrical power with an upstream speed of the water of $2.5 \mathrm{~m} / \mathrm{s}$.

The best tidal energy turbine is claimed to have a peak hydrodynamic power coefficient of about 0.48 for both rotors on both tides [28], very close to the best wind energy turbines having peak aerodynamic power coefficient of about 0.45-0.5. However, the overall system efficiency, including all losses in the generator, gearbox and power electronics, is claimed to be in the range 0.3 to 0.45 .

The Doman rotor is a $0.782 \mathrm{~m}$ diameter, turbine tested at Strathclyde, UK [17]. This is a 3-blades $1 / 20^{\text {th }}$ scale NREL S814 tidal turbine rotor. The rotor radius is $0.381 \mathrm{~m}$. The blade length is $0.292 \mathrm{~m}$. The rotor performances were tested from very low tip speed ratios to run-away, from 60 to $161 \mathrm{rpm}$, for four carriage speeds, 0.5 to $1 \mathrm{~m} / \mathrm{s}$. The coefficient of power, $C_{P}$, which describes the efficiency of a rotor in capturing the available energy in a stream tube of the same diameter, is defined as:

$$
C_{P}=\frac{T \cdot \omega}{\frac{1}{2} \cdot \rho \cdot A \cdot c^{3}}
$$

In this equation, $\mathrm{T}$ is the rotor torque momentum and $\omega$ the speed of rotation of the rotor. This $\mathrm{C}_{P}$ is the hydrodynamic power coefficient $\eta_{a}$ in equations. (5) and (6). [17] also adopts a coefficient of thrust, $C_{T}$, which describes the axial thrust experienced by the rotor, caused by the change in fluid pressure, defined as

$$
C_{T}=\frac{F}{\frac{1}{2} \cdot \rho \cdot A \cdot c^{2}}
$$

In this equation, $\mathrm{F}$ is the axial thrust force. The tip speed ratio is then

$$
T S R=\frac{R \cdot \omega}{c}
$$


with $\mathrm{R}$ the rotor tip radius. Maximum $\mathrm{C}_{P}$ of 0.285 and a maximum $\mathrm{C}_{T}$ of 0.452 was recorded at TSR of 3.53 and 4.45 for a carriage speed of $1 \mathrm{~m} / \mathrm{s}$.

The Bahaj rotor is a $0.8 \mathrm{~m}$ diameter, turbine tested at Southampton, UK [18]. This is also a 3-blades small scale tidal turbine rotor. The blades were developed from the profile shape of a NACA $63-8 x x$. The largest $C_{P}$ of about 0.45 was found at TSR of about 6 with a carriage speed of $1.73 \mathrm{~m} / \mathrm{s}$. Corresponding $\mathrm{C}_{T}$ was 0.8 . The largest $\mathrm{C}_{T}$ of about 1 was found at TSR of about 6 with a carriage speed of $1.4 \mathrm{~m} / \mathrm{s}$.

While cavitation was an issue with tidal turbines in shallow waters or close to the surface, with the occurrence of cavitation running higher speed of rotation in the design of [17] and [18], oceanic current turbines located on the ocean floor, in relatively deeper waters, do not have this issue.

\section{Sample designs of full scale marine hydrokinetic turbines}

There is limited information available about the operation of large tidal turbines, as well as of smaller turbines for river estuaries. As a reference, Figure 2.a presents a reference measured power coefficient of one of the wind turbines of [19], the E-44 [20]. Figure 2.b is the power curve. This is the smaller turbine of the family, however, the one that is delivering the best peak power coefficient. The peak power coefficient is about 0.5. For the largest rotors, the peak power coefficients are slightly smaller, about $10 \%$ less.

Figure 2.c then presents a reference power coefficient curve of a SeaGen-S 2 MW tidal turbine [29]. In this case, the peak power coefficient is 0.41. Figure 2.d presents the power curve. The shape of the power curve is relatively far from the expected for a classic single-rotor 3-blades design and flow control of modern wind turbines.

Figure 3 consists of two images of the two rotors SeaGen turbine, and of the predecessor, the single rotor SeaFlow turbine, with the rotors raised for maintenance. With a diameter of $20 \mathrm{~m}$, the SeaGen has a swept area of $628 \mathrm{~m}^{2}$ for 2 rotors. The rotor speed is 4 to $11.5 \mathrm{rpm}$. The power regulation is achieved through active blade pitch regulation. The transmission is through a planetary gearbox. An asynchronous generator delivers up to $1000 \mathrm{~kW}$ of power through a cable at $690 \mathrm{~V}$. The tower is a cylindrical tubular steel design. Rated power is $2.5 \mathrm{~m} / \mathrm{s}$.

Figure 4 finally presents the performances of the SMART mono float and SMART freestream turbines, and of the Guinard P164 turbine. The Guinard P164 is ducted, same as the SMART freestream, but with a larger bell mouth-inlet-to-rotor diameter ratio. Comparison of these small river turbines gives an idea of the advantages of "ducted" designs once applied to oceanic current turbines, that however are expected to operate at much larger depths. The SEaGen $2 \mathrm{MW}$ is shown for comparison.

\section{Survey of marine current turbines of MW-level capacity}

The research turbines of $[17,33]$ and $[18]$ are all open, axial flow, single rotor turbines, with 3 blades per rotor. This configuration is the most popular design proposed so far.

The review of [34] concludes that for the harvesting of tidal currents axial turbine systems seem better suited. the open or ducted system can be selected. The ducted turbine with diffuser and Venturi's system gives more power than the open type but costs more.

[35] reviews the latest achievements in the megawattlevel marine current turbine technologies, and, as expected, they are all horizontal axis turbines. Nearly half of the designs adopt fixed-pitch blades. These industrialized large current turbine technologies have sea-bottom supporting structures.

The basic performance characteristics of the industrialized MW-level marine current turbines of [35] and [36] are summarized in Table 2 . These turbines have a capacity from 1 to $2 \mathrm{MW}$, with corresponding rated current speeds from 2.6 to $4.0 \mathrm{~m} / \mathrm{s}$. The maximum turbine power coefficients are estimated from 0.31 to 0.44 .

The Atlantis AR1500 and Seagen-U [29] are commercial products that have passed all the preliminary tests. The two turbine systems are currently available for sale. The 1.5MW AR1500 system designed by Lockheed Martin Corporation, and the 1.5MW SeaGen U turbine originally designed by Siemens, are also described in [36] and [37].

All the tidal turbines of [36], may be fixed to the seabed either via a gravity base or fixed (drilled) pylons. They are connected to the grid via an armored power export cable. They may have active pitch and yaw. A typical turbine has an operational life of 25 years, with a 5-year maintenance cycle. Different from a wind turbine, all the power conditioning equipment (inverters, converters, and frequency controllers) are located onshore in the substation building. All key operational systems have redundancy built in to maximize reliability offshore.

The AR1500 [29] has rated operational speed of $3.0 \mathrm{~m} / \mathrm{s}$ (maximum operational speed is $5.0 \mathrm{~m} / \mathrm{s}$ ). The turbine 

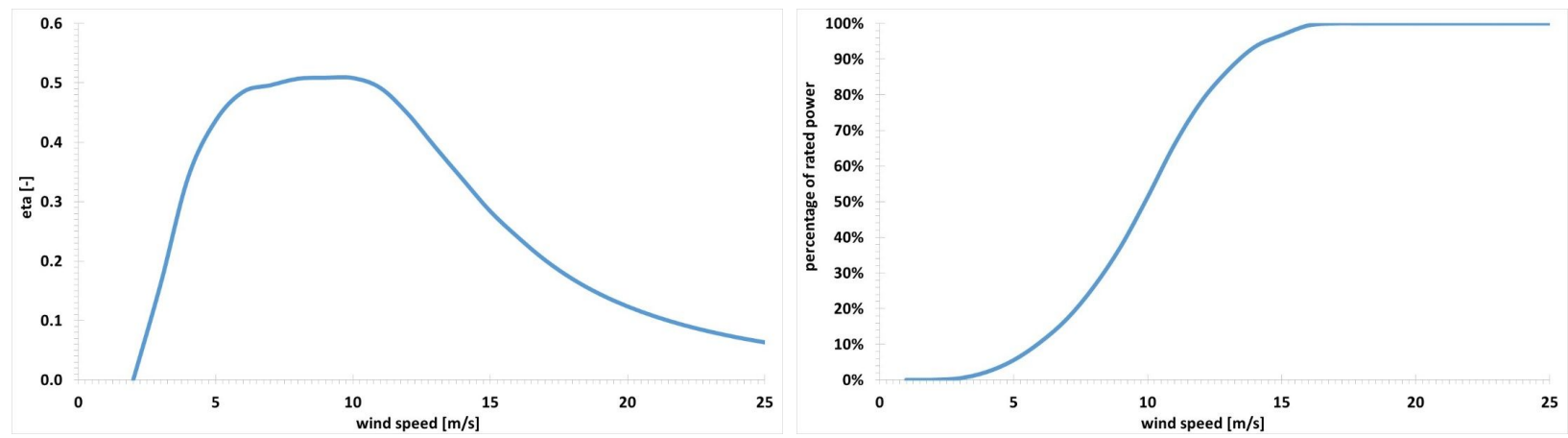

(a)

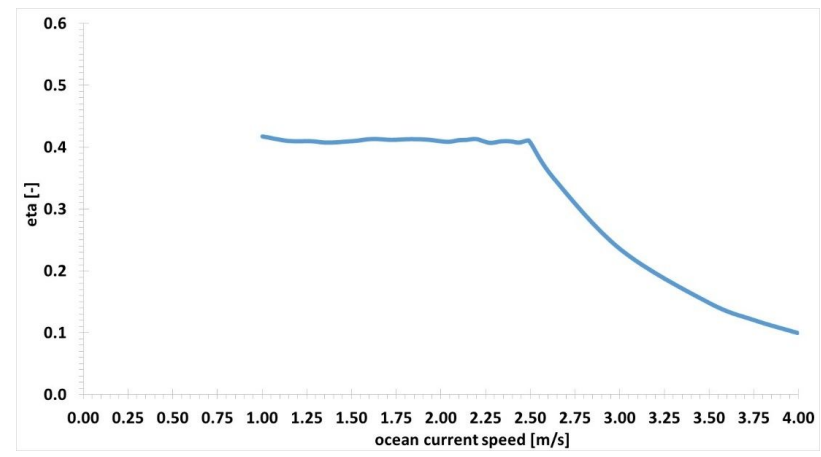

(c) (b)

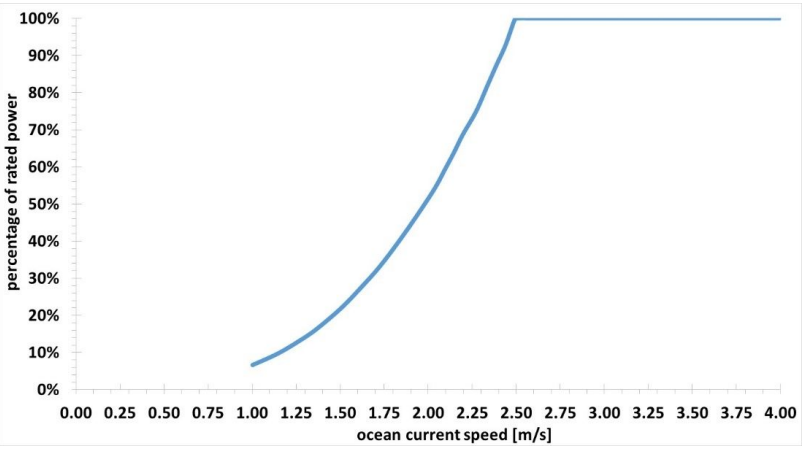

(d)

Figure 2: a) and b) Experimental power coefficient and power curve of a 900-kW wind turbine Enercon E-44. The rotor number is 1 , the blade number per rotor is 3 , the rotor diameter is $44 \mathrm{~m}$. Hub height is $45 / 55 \mathrm{~m}$. The power coefficients are computed from the power and speed data proposed in [20]. c) and d) Experimental power coefficient and power curve of an ocean current turbine SeaGen-S 2 MW. The number of rotors is 2 , the blade number per rotor is 2 , the rotor diameter is $20 \mathrm{~m}$. The power coefficients are computed from the power and speed data proposed in [29].

Table 2: Performance characteristics of industrialized large marine current turbines

\begin{tabular}{|c|c|c|c|c|c|c|c|}
\hline Device & $\begin{array}{r}\text { DCNS Open } \\
\text { Hydro }\end{array}$ & $\begin{array}{l}\text { Atlantis } \\
\text { AR1000 }\end{array}$ & Voith & $\begin{array}{r}\text { Sabella } \\
\text { D10 }\end{array}$ & $\begin{array}{r}\text { GE-Alstom } \\
1 \mathrm{MW}\end{array}$ & $\begin{array}{l}\text { Atlantis } \\
\text { AR1500 }\end{array}$ & $\begin{array}{r}\text { Atlantis } \\
\text { SeaGen-S } \\
2 M W\end{array}$ \\
\hline Reference & [35] & [35] & [35] & [35] & [35] & {$[29,36]$} & {$[29,36]$} \\
\hline Rated power (MW) & 2 & 1 & 1 & 1.1 & 1 & 1.5 & 2 \\
\hline Rated current speed $(\mathrm{m} / \mathrm{s})$ & 4 & 2.65 & 2.9 & 4 & 2.7 & 3 & 2.5 \\
\hline Rotor number & 1 & 1 & 1 & 1 & 1 & 1 & 2 \\
\hline Blade number (one rotor) & 10 & 3 & 3 & 6 & 3 & 3 & 2 \\
\hline Rotor diameter $(m)$ & 16 & 18 & 16 & 10 & 18 & 18 & 20 \\
\hline Blade swept area $\left(\mathrm{m}^{2}\right)$ & 201.06 & 254.47 & 201.06 & 78.54 & 254.47 & 254.47 & 314.16 \\
\hline Estimated $\eta$ value & 0.31 & 0.42 & 0.41 & 0.44 & 0.40 & 0.44 & 0.41 \\
\hline
\end{tabular}

length is $12 \mathrm{~m}$, the weight in the air is 150 tons. The rotor has blade diameter $18 \mathrm{~m}$, and hub diameter $2.4 \mathrm{~m}$. The blades are pitch-able. The generator is radial flux PMG of rating $1500 \mathrm{~kW}$, operating with a voltage of $4.16 \mathrm{kV}$ and an efficiency of $97 \%$. The gearbox is a Two-Stage Planetary Flexi-Pin of rating 1500 kW @ 14 rpm and Ratio 1:27. The power conversion is a Four Quadrant MV Converter of rating $1500 \mathrm{~kW}$. There is a Yaw Drive System.
Despite developed for tidal stream applications in relatively shallow waters, the AR1500 has the potential of a nearly drop-in solution for oceanic currents applications, even if some changes are certainly needed to work with the reduced carriage speeds of oceanic currents in deeper waters. 


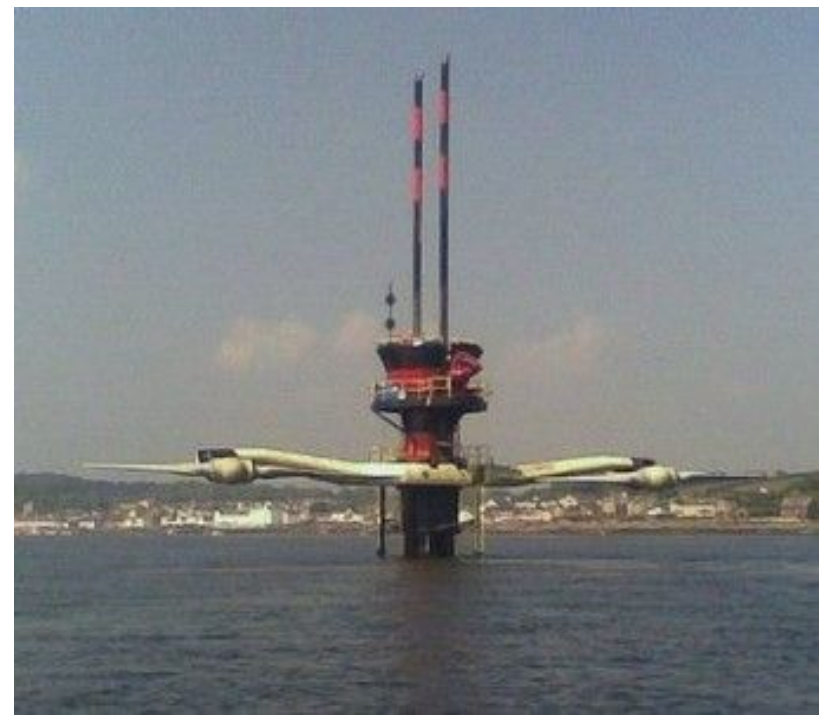

(a)

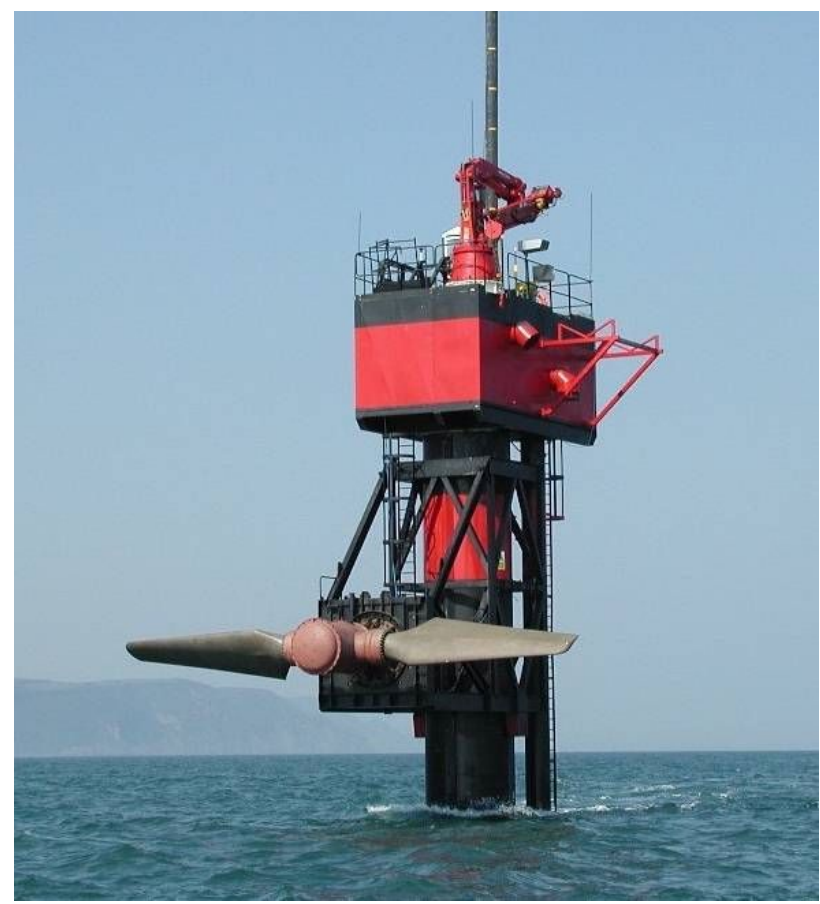

(b)

Figure 3: a) Two rotors SeaGen turbine, with the rotors raised for maintenance. Image from [30]. By Fundy - Own work. CC BY-SA 3.0. b) Single rotor SeaFlow turbine, with the rotor raised for maintenance. Image from [31]. By Fundy - Own work. CC BY-SA 3.0

\section{Discussion and conclusions}

The marine current turbines presently industrialized, however for tidal rather than oceanic currents, are all horizontal axis turbines with sea-bottom supporting structures. Most of these turbines have fixed-pitch blades.

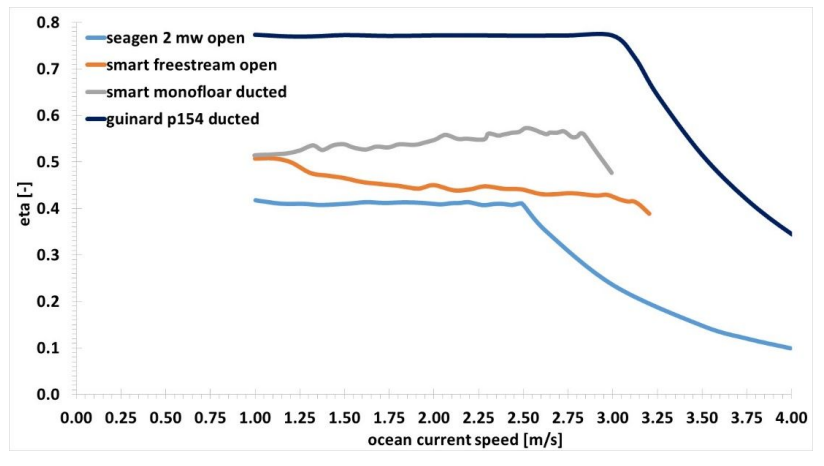

(a)

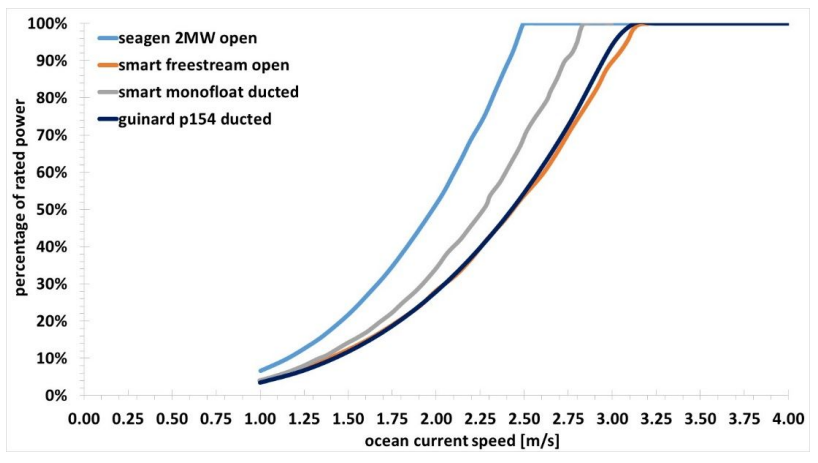

(b)

Figure 4: a) and b) Experimental power coefficient and power curve of a 5-kW river turbine SMART mono float, SMART freestream, and $20 \mathrm{~kW}$ river turbine Guinard P164. For the SMART turbine, the rotor number is 1 , the blade number per rotor is 3 , the rotor diameter is $1 \mathrm{~m}$. The mono float is open; the freestream is ducted. The power coefficients are computed from the power and speed data proposed in [9]. For the Guinard P164 turbine, the rotor number is 1, the blade number per rotor is 2, the rotor diameter is $1.5 \mathrm{~m}$. The Guinard P164 is ducted, with the bell mouth inlet diameter $2.3 \mathrm{~m}$. The power coefficients are computed from the power and speed data proposed in [32].

The floating/buoyant turbine systems under development can have advantages due to easy installation and accessibility, their operation under strong sea conditions is still unproven. At least the first generation of oceanic current turbines, to be installed in pilot oceanic current turbine farms in the coming years, will be axial flow, open turbines, with 3-blades, anchored to the ocean floor, derived from tidal turbines, and closely resembling underwater wind farm installations. A major break-through in the harvesting technology would be the opportunity to transfer mechanical energy from the underwater to onshore, removing from the water all the electrical components. Worth of study, the transmission of power by vibrations (theory of sonics, [39]). Following a proper measurement campaign with velocity probes and sonar in the best locations for the oceanic current resource, stability, intensity, 
non-excessive depth, proximity to shore, and favorable topography of the ocean floor, to properly address the siting issue, it is expected that such turbines will be installed and start producing electricity within the next decade, paving the way for further progress.

Acknowledgment: The author received no financial support and declares no conflict of interest.

\section{References}

[1] International Energy Agency, Key world energy statistics, 2018. webstore.iea.org/download/direct/2291?fileName= Key_World_2018.pdf

[2] U.S. Energy Information Administration, Electricity Data Browser, 2019. http://www.eia.gov/electricity/data/browser/

[3] Bureau of Ocean Energy Management, Ocean Current Energy, n.d., https://www.boem.gov/Ocean-Current-Energy/

[4] The Ocean Energy Council, What is ocean energy?, n.d., http: //www.oceanenergycouncil.com/ocean-energy/

[5] Australian Government Geoscience Australia, Ocean Energy, n.d., http://www.ga.gov.au/energy/other-renewable-energyresources/ocean-energy.html

[6] Parker A., Deep ocean currents energy resources-A case study of Australia, World J. Model. Simul., 11(3), 2015, 163-173.

[7] National Renewable Energy Laboratory, NWTC Information Portal, n.d., https://nwtc.nrel.gov/technology-type/marinehydrokinetics

[8] Ragheb, M. and Ragheb, A. M. , Wind Turbines Theory - The Betz Equation and Optimal Rotor Tip Speed Ratio, in Fundamental and Advanced Topics in Wind Power, Dr. Rupp Carriveau (Ed.), InTech, 2011.

[9] Smart-Hydro, Hydrokinetic turbines, n.d., http://www.smarthydro.de/renewable-energy-systems/hydrokinetic-turbinesriver-canal/

[10] Werle, M.J. and Presz, W.M., Ducted wind/water turbines and propellers revisited, J. Propul. Power, 2008, 24(5), 1146-1150.

[11] Chihaia, R.A., El-Leathey, L.A., Cîrciumaru, G. and Tănase, N., Increasing the energy conversion efficiency for shrouded hydrokinetic turbines using experimental analysis on a scale model. In E3S Web of Conferences (Vol. 85, p. 06004), EDP Sciences, 2019.

[12] Hansen, M.O., Aerodynamics of wind turbines, Routledge, 2015.

[13] Kulunk, E., Aerodynamics of wind turbines. In Fundamental and Advanced Topics in Wind Power, InTech, 2011.

[14] Sun, Z., Chen, J., Shen, W.Z. and Zhu, W.J., Improved blade element momentum theory for wind turbine aerodynamic computations, Renewable Energy, 2016, 96, 824-831.

[15] Masters I., Chapman J.C., Willis M.R., Orme J.A.C., A robust blade element momentum theory model for tidal stream turbines including tip and hub loss corrections, J. Marine Eng. Technol., 2011, 10(1), 25-35.

[16] National Renewable Energy Laboratory, AeroDyn, n.d., https: //nwtc.nrel.gov/AeroDyn.

[17] Doman D.A., Murray R.E., Pegg M.J., Gracie K., Johnstone C.M.,
Nevalainen T., Tow-tank testing of a $1 / 20^{\text {th }}$ scale horizontal axis tidal turbine with uncertainty analysis, Int. J. Marine Energy, 2015, 11, 105-119.

[18] Bahaj A.S., Molland A.F., Chaplin J.R., Batten W.M.J., Power and thrust measurements of marine current turbines under various hydrodynamic flow conditions in a cavitation tunnel and a towing tank, Renew. Energy, 2007, 32(3), 407-426.

[19] Enercon, Overview of ENERCON platform, n.d., https://www. enercon.de/en/products/ep-1/e-44/

[20] Enercon, E-44 n.d., www.enercon.de/en/products/ep-1/e44/

[21] The European marine energy center, Tidal developers, n.d., www.emec.org.uk/marine-energy/tidal-developers/

[22] Ross D.A., Introduction to Oceanography. HarperCollins, New York, NY, 1995.

[23] Belloni C.S., Hydrodynamics of ducted and open-center tidal turbines, Doctoral dissertation, 2013, University of Oxford.

[24] Bahaj A.S., Myers L.E., Fundamentals applicable to the utilisation of marine current turbines for energy production, Renew. Energy, 2003, 28(14), 2205-2211.

[25] Florida Atlantic University, Experimental Ocean Current Turbine, n.d., coet.fau.edu/projects/experimental-ocean-currentturbine.html

[26] Hanson H.P., Bozek A., Duerr A.E.S. , The Florida Current: A Clean but Challenging Energy Resource, Eos Trans. AGU, 2011, 92(4), 29.

[27] Yuce M.I., Muratoglu A., Hydrokinetic energy conversion systems: A technology status review, Renew. Sustain. Energy Rev., 2015, 43, 72-82.

[28] Renewable energy focus, DNV confirms SeaGen's powerful performance, 2010 , www.renewableenergyfocus.com/view/12197/dnv-confirmsseagen-tidal-turbine-performance/

[29] SIMEC at Atlantis Energy, SEAGEN-S. n.d., https:// simecatlantis.com/wp/wp-content/uploads/2016/08/ SeaGen-Brochure.pdf

[30] https://upload.wikimedia.org/wikipedia/commons/e/e1/ Seagenraised.jpg

[31] en.wikipedia.org/wiki/Marine_Current_Turbines\#/media/File: Seaflow_raised_16_jun_03.jpg

[32] Guinard, P154 turbine. n.d., http://www.guinard-energies. bzh/wp-content/uploads/2017-P154-Flyer.pdf

[33] Duerr A., Hydrokinetic Power Resource Assessment of the Florida Current Assessment of the Florida Current, 2010, http: //www.ces.fau.edu/coet/presentations/COET006_Duerr_ BlueWater.pdf

[34] Güney M.S., Kaygusuz K., Hydrokinetic energy conversion systems: A technology status review, Renew. Sustain. Energy Rev., 2010, 14(9), 2996-3004.

[35] Zhou Z., Benbouzid M., Charpentier J.F., Scuiller F., Tang T., Developments in large marine current turbine technologies-A review, Renew. Sustain. Energy Rev., 2017, 71, 852-858.

[36] SIMEC at Atlantis Energy, Tidal Turbines, n.d., simecatlantis. com/services/turbines/

[37] SIMEC at Atlantis Energy, AR1500, N.D., https://simecatlantis. com/wp/wp-content/uploads/2016/08/AR1500-BrochureFinal-1.pdf

[38] Constantinesco G., Theory of Sonics: A Treatise on Transmission of Power by Vibrations. The Admiralty, London, 1918. 